ORIGINAL ARTICLE

\title{
Age at exposure to ionising radiation and cancer mortality among Hanford workers: follow up through 1994
}

\author{
S Wing, D B Richardson
}

Occup Environ Med 2005;62:465-472. doi: 10.1136/oem.2005.019760

See end of article for authors' affiliations .....................

Correspondence to: Prof. S Wing, Department of Epidemiology, School of Public Health, CB\#7435, University of North Carolina, Chapel Hill, NC 27599-7400, USA; steve_wing@unc.edu

Accepted 17 March 2005
Background: Studies of workers at the plutonium production factory in Hanford, WA have led to conflicting conclusions about the role of age at exposure as a modifier of associations between ionising radiation and cancer.

Aims: To evaluate the influence of age at exposure on radiation risk estimates in an updated follow up of Hanford workers.

Methods: A cohort of 26389 workers hired between 1944 and 1978 was followed through 1994 to ascertain vital status and causes of death. External radiation dose estimates were derived from personal dosimeters. Poisson regression was used to estimate associations between mortality and cumulative external radiation dose at all ages, and in specific age ranges.

Results: A total of 8153 deaths were identified, 2265 of which included cancer as an underlying or contributory cause. Estimates of the excess relative risk per Sievert (ERR/Sv) for cumulative radiation doses at all ages combined were negative for all cause and leukaemia and positive for all cancer and lung cancer. Cumulative doses accrued at ages below 35, 35-44, and 45-54 showed little association with mortality. For cumulative dose accrued at ages 55 and above (10 year lag), the estimated ERR/Sv for all cancers was 3.24 (90\% Cl: 0.80 to 6.17), primarily due to an association with lung cancer (ERR/Sv: 9.05, $90 \% \mathrm{Cl}: 2.96$ to 17.92$)$.

Conclusions: Associations between radiation and cancer mortality in this cohort are primarily a function of doses at older ages and deaths from lung cancer. The association of older age radiation exposures and cancer mortality is similar to observations from several other occupational studies.
A number of national and international regulatory and advisory organisations report radiation risk estimates for cancer following exposure to external ionising radiation. ${ }^{12}$ These risk estimates are primarily based on the results of studies of populations exposed to radiation at high doses and dose rates, particularly studies of Japanese atomic bomb survivors. Because most environmental and occupational exposures to ionising radiation occur at low doses and dose rates, epidemiological studies of protracted low level exposures are of interest because they provide an empirical basis for evaluating the appropriateness of extrapolation of dose-response estimates from high dose studies that are used for radiation risk assessments, protection standards, and compensation decisions.

The Hanford Site was the first US nuclear weapons plant to be the subject of an epidemiological cohort study in which occupational radiation doses were examined in relation to cancer rates. Initial findings were reported in the 1970s. ${ }^{34}$ Mancuso et al reported evidence of positive associations between external exposure to ionising radiation and mortality from "cancers of radiosensitive tissues", ${ }^{4-6}$ and, in later analyses, positive associations with mortality from all cancers combined. ${ }^{7}$ In their analyses, associations between ionising radiation and cancer were highly dependent on age at exposure, with evidence for dose-response relations primarily due to the effects of exposures received at the oldest ages. ${ }^{7-9}$ Gilbert et al also examined mortality of Hanford workers, finding little or no evidence for relations between cumulative external radiation dose and cancer $^{10}$ with the exception of multiple myeloma, which they found to be associated with radiation exposures in earlier, ${ }^{11}$ but not later $^{10}$ follow up. Gilbert et al reported positive associations at older ages at risk, but postulated that this finding was the result of unspecified biases. $^{12}$
Although increased susceptibility to ionising radiation at older adult ages is plausible given age related functional declines in cellular repair processes, ${ }^{13}{ }^{14}$ most studies of atomic bomb survivors suggest decreasing sensitivity to radiation with advancing age. While lung cancer relative risks among atomic bomb survivors increase with age at exposure, this could be due to variation in smoking habits by birth cohort rather than increased radiation sensitivity with age at exposure. ${ }^{15}$

In this paper we use standard epidemiological methods for analysis of time windows ${ }^{16}$ to evaluate evidence of age modification of dose-response relations between external ionising radiation and mortality of Hanford workers.

\section{METHODS}

Approval for this research was obtained from the University of North Carolina Institutional Review Board for research involving human subjects.

\section{Study cohort: definition and follow up}

Records for 33459 Hanford workers were obtained from the National Institute for Occupational Safety and Health. Cohort members were employed by primary contractors for the Hanford Site (including Boeing, DuPont, General Electric, and Westinghouse) for at least 180 days, had at least one record indicating they were monitored for external radiation, and had been hired between 1944 and 1978 .

We excluded two workers with annual external radiation doses above $250 \mathrm{mSv}$, which is above the standard threshold for studies of low dose and low dose rate exposures, and two workers acutely exposed in radiation accidents. Workers employed at other nuclear weapons sites were excluded because dose records for those employment periods were not available. To limit problems of missing dosimetry data and 
Main messages

- Associations between ionising radiation and cancer mortality among Hanford workers are primarily a function of doses at older ages and deaths from lung cancer.

avoid long periods of worker selection prior to start of follow up, we also excluded employees who were first hired more than two years prior to their first external dose record or achieving 180 days of employment by a prime contractor. Vital status follow up was conducted through 31 December 1994 using records of the National Death Index, Social Security Administration, Health Care Financing Agency, Pension Benefits, and the Washington State Department of Licensing. The National Death Index (NDI) has been shown to provide virtually complete ascertainment of deaths among employed men and women in the United States beginning in $1979,{ }^{17}$ so individuals known to be alive on 1 January 1979 or later were assumed to be alive at the end of the study if there was no indication of death from NDI. Underlying and contributory causes of death, obtained from state departments of vital statistics, were coded to the ninth revision of the International Classification of Diseases (ICD-9). Primary mortality analyses were conducted for total mortality, mortality from all cancers combined (any death with an ICD-9 code of 140-208 as an underlying or contributory cause), lung cancer (any death with an ICD-9 code of 162), and leukaemia except chronic lymphocytic leukaemia (CLL, ICD-9 200-208 except 204.1), a subtype of leukaemia that is often characterised by long latency and low case fatality, and which may differ from other leukaemias in its degree of radiogenicity. ${ }^{18}$

\section{Radiation dose estimates}

Estimated doses from external ionising radiation, primarily gamma rays, and tritium, are the major focus of this analysis. Hanford radiation dosimetry programmes have been described in detail previously..$^{20}$ Computerised annual dosimetry records were obtained for 1944 through 1989. ${ }^{21}$ Although annual dose records were available for most production workers in most years, a substantial proportion of missing values occurred in earlier time periods, especially for clerical workers and women. ${ }^{20}$ Missing values were estimated by a 13 step algorithm that relied on each worker's dose in neighbouring years, and, if not available, on the mean dose for workers of the same occupation and sex in the same year. ${ }^{20}$

\section{Policy implications}

- Evidence from studies of cancer following protracted exposure to low level ionising radiation is relevant to occupational and environmental radiation protection standards and to worker compensation programmes.

\section{Statistical analysis}

An SAS computer program ${ }^{22}$ was used to tabulate persondays and deaths in categories defined by the crossclassification of cumulative radiation dose and covariates of interest: age-at-risk, birth cohort, race, sex, socioeconomic status (SES), employment status, in vivo monitoring, and plutonium exposure potential. Age-at-risk was categorised in five year intervals. Birth year was grouped as before 1900, and in decade intervals up to 1940 or later. Race groups were African American, white, and other. Three categories of SES were defined according to the occupational prestige of each worker's longest held job: administrative/professional, clerical/skilled manual, or semi-skilled/unskilled manual. Employment status categories were: actively employed, one to two years post-termination, or more than two years posttermination, classified separately for risk ages less than 45 , $45-62$, and 62 or greater, a method developed to control bias due to healthy worker survival. ${ }^{23}$ Workers were classified as in vivo monitored beginning on the day of their first monitoring result; this was used as an indicator of selection of healthier workers into exposed jobs because it has been shown to be related to higher radiation exposure and lower mortality in past studies of Hanford workers. ${ }^{82425}$ We used industrial process and work history records to create a job-exposure matrix for potential exposure to plutonium. ${ }^{25}$ Workers were classified as potentially exposed to plutonium, starting on their first day of employment in a job with routine plutonium exposure potential.

The primary exposure of interest, external ionising radiation, was treated in a time dependent fashion. Doses were recorded on a calendar year basis. Age at exposure was assigned to annual doses based on age at the midpoint of the monitoring year. Cumulative doses were tabulated in four age windows: <35; 35-44; 45-54; and 55+ years. Doses in each age range were accumulated under 5, 10, and 15 year lag assumptions to account for time intervals between exposure and resultant death. Dose groups were defined as $0,-10$, $-20,-50,-100,-150,-200,-300$, and $300+\mathrm{mSv}$. The mean cumulative dose for the person-days in each cell of the tables defined by the cross-classification of all covariates was used for calculation of dose-response coefficients.

Table 1 Hanford Site cohort definition and vital status through 31 December 1994

\begin{tabular}{lccc}
\hline & Men & Women & Total \\
\hline Operations workers hired 1944-78 & 25314 & 8145 & 33459 \\
Exclusions & 352 & 29 & 381 \\
$\quad$ First employed in construction & 2934 & 230 & 3164 \\
Offsite dose (30 person Sv) & 1112 & 104 & 1216 \\
Employed at other DOE facility & 1232 & 1077 & 2309 \\
2+ years between first hire and & & & \\
eligibility & & & \\
Study cohort & $12279(62.4)$ & $5532(82.6)$ & $17811(67.5)$ \\
Vital status & $7272(36.9)$ & $881(13.1)$ & $8153(30.9)$ \\
$\quad$ live & $133(0.7)$ & $292(4.4)$ & $425(1.6)$ \\
Dead & $19684(100.0)$ & $6705(100.0)$ & $26389(100.0)$ \\
$\quad$ Unknown & & & \\
$\quad$ Total & & & \\
\hline
\end{tabular}


Table 2 Characteristics of Hanford Site workers

\begin{tabular}{|c|c|c|c|c|c|c|}
\hline & \multicolumn{2}{|l|}{ Men } & \multicolumn{2}{|c|}{ Women } & \multicolumn{2}{|l|}{ Total } \\
\hline & $n$ & $\%$ & $n$ & $\%$ & $n$ & $\%$ \\
\hline \multicolumn{7}{|l|}{ Year of hire } \\
\hline $1944-47$ & 6516 & 33.1 & 899 & 13.4 & 7415 & 28.1 \\
\hline $1948-59$ & 5683 & 28.9 & 2085 & 31.1 & 7768 & 29.4 \\
\hline $1960-89$ & 7485 & 38.0 & 3721 & 55.5 & 11206 & 42.5 \\
\hline \multicolumn{7}{|l|}{ Birth cohort } \\
\hline $1873-99$ & 1436 & 7.3 & 97 & 1.4 & 1533 & 5.8 \\
\hline $1900-09$ & 2228 & 11.3 & 252 & 3.8 & 2480 & 9.4 \\
\hline $1910-19$ & 3910 & 19.9 & 708 & 10.6 & 4618 & 17.5 \\
\hline $1920-29$ & 4479 & 22.8 & 1294 & 19.3 & 5773 & 21.9 \\
\hline $1930-39$ & 3297 & 16.7 & 1373 & 20.5 & 4670 & 17.7 \\
\hline $1940-58$ & 4334 & 22.0 & 2981 & 44.5 & 7315 & 27.7 \\
\hline \multicolumn{7}{|l|}{ SES } \\
\hline Unskilled manual & 8199 & 41.7 & 1778 & 26.5 & 9977 & 37.8 \\
\hline Skilled manual & 5843 & 29.7 & 4451 & 66.4 & 10294 & 39.0 \\
\hline Tech/managerial & 5642 & 28.7 & 476 & 7.1 & 6118 & 23.2 \\
\hline \multicolumn{7}{|l|}{ In vivo monitoring } \\
\hline Never & 11144 & 56.6 & 4621 & 68.9 & 15765 & 59.7 \\
\hline Ever & 8540 & 43.4 & 2084 & 31.1 & 10624 & 40.3 \\
\hline \multicolumn{7}{|l|}{ Plutonium worker } \\
\hline Never & 17011 & 86.4 & 6313 & 94.2 & 23324 & 88.4 \\
\hline Ever & 2673 & 13.6 & 392 & 5.8 & 3065 & 11.6 \\
\hline
\end{tabular}

Poisson regression models were estimated using the Epicure software package. ${ }^{26}$ We present dose-response findings from excess relative risk regression models considering the relative risk (rate ratio) as a function of $1+\beta$ dose, where $\beta$ represents the excess relative risk per Sv (ERR/Sv). Exponential relative risk models, in which the death rate is a function of $\exp$ ( $\beta$ dose) were also fit (see Appendix). Control for potential confounding by age-at-risk, birth cohort, race, sex, SES, employment status, and in vivo monitoring was obtained by background stratification. Following previous work suggesting the possibility of a larger relative impact of external radiation among workers with internal contamination from alpha emitting radionuclides, ${ }^{27}$ the indicator variable for employment in a job with routine potential for plutonium exposure was estimated as a main effect so that its interaction with dose could be examined. For analyses of age-at-exposure, separate $\beta$ parameters were estimated for each of four time window specific dose terms. The change in deviance on inclusion of a dose term in the regression model, described as a likelihood ratio test (LRT) statistic, can be interpreted using a $\chi^{2}$ distribution with one degree of freedom. In age specific dose models, LRT values were calculated for each dose term by comparing the deviance of a model without each age specific dose term to the full model including all age specific dose terms. LRT values are reported instead of $p$ values to reduce emphasis on statistical significance, which is inappropriately applied in observational studies. ${ }^{28}$ Following convention in the radiation epidemiology literature, we present 90\% likelihood based confidence intervals for the excess RR coefficients. We present confidence intervals because they provide more information than $\mathrm{p}$ values and, like the LRT tests, encourage interpretation of results along a more continuous scale with emphasis on precision rather statistical "significance" testing. ${ }^{29}$

\section{RESULTS}

The study cohort is described in table 1. Men were excluded primarily because of employment at other sites $(n=2934)$, whereas women were primarily excluded due to extended employment prior to first radiation monitoring $(\mathrm{n}=1077)$. Among the cohort of 26389 workers, 67.5\% were alive at the end of 1994, 1.6\% were lost to follow up, and 8153 deaths were identified. Cause of death information was obtained for $98.9 \%$ of deaths.

Most men were hired before 1960, while most women were hired after 1960, a difference that is reflected in the younger distribution of women's birth years (table 2). A total of $41.7 \%$ of men and $26.5 \%$ of women were classified as unskilled manual workers, while $28.7 \%$ of men and $7.1 \%$ of women were classified as technical or managerial workers. Most workers were never monitored by in vivo gamma spectroscopy. Jobs with routine potential for plutonium exposure were held by $13.6 \%$ of men and $5.8 \%$ of women.

Age specific radiation exposures were dependent on ages of hire and termination from employment (table 3). More than $70 \%$ of workers were hired before age 35 and about a quarter terminated employment after age 55. Workers hired at younger ages also tended to leave at younger ages: 6814 of the 9545 cohort members hired at ages below 25 terminated by age 35 , whereas 720 worked past age 55 . In contrast, 2162 of the 2919 workers hired at ages 45 and above worked beyond the age of 55 .

Mean and median doses for all ages were 27.9 and $4.3 \mathrm{mSv}$, respectively (table 4). Over 3000 workers had cumulative doses above $50 \mathrm{mSv}$. Age specific dose distributions in table 4 include workers with at least one recorded or estimated dose in each age range; workers whose age specific doses are zero because they were not employed at those ages were not counted in age specific dose distributions. Mean and median doses tended to be higher at ages 45 and above than at younger ages. Maximum doses in the three younger age groups were between 342 and $352 \mathrm{mSv}$, while the maximum dose above age 55 was $402.8 \mathrm{mSv}$.

Table 5 shows that ERR coefficients for doses at all ages are negative for all cause mortality and leukaemia, positive for all cancer and lung cancer, and show little variability with lag. For all cancer and lung cancer, ERR coefficients (90\% CI) are $0.28(-0.30$ to 1.00$)$ and 1.31 (0.05 to 3.11$)$, respectively, for a 10 year lag assumption. Largest LRT values, approximately 3, occur for lung cancer under five and ten year lag assumptions. Although maximum likelihood estimates of ERR coefficients for leukaemia were obtained, likelihood based confidence intervals were not found (Appendix).

Numbers of deaths were large enough to estimate age specific coefficients for all causes, all cancers, and lung cancers (table 6). For all cause mortality $(n=8153)$, most 
Table 3 Distribution of workers according to ages at hire and termination from employment at the Hanford Site, 1944-89

\begin{tabular}{|c|c|c|c|c|c|}
\hline \multirow[b]{2}{*}{ Age at hire } & \multicolumn{4}{|c|}{ Age at termination } & \multirow[b]{2}{*}{ Total (\%) } \\
\hline & $16-34$ & $35-44$ & $45-54$ & $55-82$ & \\
\hline $15-24$ & 6814 & 1277 & 734 & 720 & 9545 (36.2) \\
\hline $25-34$ & 3614 & 2520 & 1183 & 2050 & $9367(35.5)$ \\
\hline $35-44$ & - & 1495 & 1175 & 1888 & 4558 (17.3) \\
\hline $45-72$ & - & - & 757 & 2162 & 2919 (11.1) \\
\hline Total (\%) & 10428 (39.5) & $5292(20.1)$ & 3849 (14.6) & $6820(25.8)$ & $26389(100)$ \\
\hline
\end{tabular}

coefficients for doses at ages below 55 are negative; age specific estimates have absolute values less than 0.6 , and LRT values less than 0.4 , except for the coefficient for cumulative doses at ages 35-44 under a five year lag, which is -0.82 (90\% CI: -1.81 to 0.24 , LRT $=1.65)$.

All cancer $(n=2265)$ risk coefficients are positive in the youngest and oldest age groups and negative in the middle age groups under all lag assumptions. In the three younger age groups, LRT values do not exceed 1.l. Larger coefficients and LRT values are observed for doses at ages 55 and above. The improvement in model fit on addition of the age $55+$ dose coefficient to models including terms for the three younger age groups is largest under a 10 year lag $($ LRT $=5.06)$; under this model the ERR/Sv is 3.24 (0.80 to 6.17).

For lung cancer $(n=666)$, most risk coefficients in the three youngest age groups are negative and LRT values are close to zero. Cumulative doses above age 55 are positively associated with lung cancer. The largest ERR/Sv, $10.28(2.42$ to 22.52), is observed for a 15 year lag, while the improvement in model fit on addition of the term for doses above age $55+$ is largest $(\mathrm{LRT}=7.33)$ under a 10 year lag, for which the ERR/Sv is 9.05 (2.96 to 17.92).

Observed deaths and observed/expected ratios for all cancer and lung cancer according to doses at ages 55+ under a 10 year lag, which provided the largest LRT values for all cancer and lung cancer, are presented in table 7. Observed/ expected ratios for all cancer and lung cancer are slightly below unity in the lowest three dose groups. The highest ratios, 1.56 and 2.51 for all cancer and lung cancer, respectively, occur in the $200-300 \mathrm{mSv}$ dose category. There is only one observed cancer death for doses in this age range above $300 \mathrm{mSv}$, and no observed lung cancers.

We compared all cancer and lung cancer ERR coefficients (10 year lag) for Hanford workers employed in jobs with routine potential for plutonium exposure $(n=3065)$ to coefficients for other Hanford workers (table 8). Based on analyses in table 6, a single parameter was estimated for cumulative doses below age 55. All cancer ERR estimates for younger and older ages are similar for plutonium workers and other Hanford workers. For lung cancer, younger age estimates are small for both groups. For cumulative doses at ages 55+, the lung cancer ERR/Sv is 24.62 (6.76 to 59.02) for plutonium workers and 7.02 (1.61 to 15.20) for other Hanford workers.

Dose-response coefficients from exponential relative risk models were similar to findings from the ERR models presented above, although LRT values tended to be somewhat smaller (data not shown). For example, the LRT values for cumulative doses at ages 55+ ( 10 year lag) were 4.44 and 5.98 for all cancer and lung cancer, respectively, compared to 5.06 and 9.05 under the ERR model.

\section{DISCUSSION}

Cumulative radiation doses accrued at all ages showed little association with mortality. The largest positive ERRs/Sv, between 1.14 and 1.31, were observed for lung cancer. Coefficients for leukaemia except CLL were negative. Findings of little association between radiation doses across all ages and mortality from all cancers are consistent with previous Hanford studies ${ }^{10}$ and an international study that included Hanford workers. ${ }^{30}$ The estimated ERR/Sv for all cancer mortality under a 10 year exposure lag assumption $(\mathrm{ERR} / \mathrm{Sv}=0.28,90 \% \mathrm{CI}:-0.30$ to 1.00$)$ can be compared to the value of -0.15 (90\% CI: $<0$ to 0.8 ) reported for follow up of Hanford workers through $1986^{10}$ and -0.02 (90\% CI -0.34 to 0.35 ) reported in a study of nuclear workers in three countries. ${ }^{30}$ In contrast, several studies of nuclear workers have found radiation doses accrued at all ages to be positively associated with mortality from all causes, all cancers, lung cancer, and leukaemia, especially under longer exposure lag assumptions. ${ }^{31-33}$

Table 4 Numbers of Hanford workers according to cumulative age specific radiation doses, 1944-89

\begin{tabular}{llllll}
\hline \multicolumn{5}{l}{ Age at exposure } \\
\cline { 2 - 6 } Cumulative dose (mSv) & $\mathbf{1 5 - 3 4}$ & $\mathbf{3 5 - 4 4}$ & $\mathbf{4 5 - 5 4}$ & $\mathbf{5 5 - 8 2}$ & $\mathbf{1 5 - 8 2}$ \\
\hline$=0$ & 2362 & 1477 & 863 & 477 & 2354 \\
$<10$ & 12359 & 8063 & 6076 & 4284 & 14853 \\
$10-49$ & 3145 & 2324 & 1968 & 1339 & 6012 \\
$50-99$ & 619 & 541 & 459 & 286 & 1301 \\
$100+$ & 428 & 546 & 602 & 357 & 1869 \\
Total (n) & 18913 & 12951 & 9968 & 6743 & 26389 \\
Mean (mSv) & 11.2 & 15.6 & 19.7 & 18.3 & 27.9 \\
Median (mSv) & 2.4 & 2.9 & 3.7 & 3.7 & 4.3 \\
Max (mSv) & 352.3 & 342.1 & 346.1 & 402.8 & 859.8 \\
\hline
\end{tabular}

*Total number of workers with at least one recorded or estimated dose in each age range. Workers whose age specific doses are zero because they were not employed at those ages were not counted in age specific dose distributions. 
Table 5 Excess relative risk per Sv at all ages, 5, 10, and 15 year lag assumptions, follow up of Hanford Site workers through 1994

\begin{tabular}{llll}
\hline $\begin{array}{l}\text { Cause of death } \\
\text { Lag (years) }\end{array}$ & ERR/Sv & (90\% Cl) & LRT (1 dft \\
\hline $\begin{array}{lll}\text { All causes } \\
5\end{array}$ & -0.04 & $(-0.32$ to 0.27$)$ & 0.06 \\
10 & -0.10 & $(-0.40$ to 0.24$)$ & 0.26 \\
15 & -0.18 & $(-0.52$ to 0.20$)$ & 0.64 \\
All cancers & & & \\
5 & 0.30 & $(-0.23$ to 0.96$)$ & 0.78 \\
10 & 0.28 & $(-0.30$ to 1.00$)$ & 0.55 \\
15 & 0.16 & $(-0.49$ to 0.98$)$ & 0.15 \\
Lung cancers & & & \\
5 & 1.22 & $(0.08$ to 2.83$)$ & 3.19 \\
10 & 1.31 & $(0.05$ to 3.11$)$ & 2.98 \\
15 & 1.14 & $(-0.22$ to 3.10$)$ & 1.77 \\
Leukaemia - CLL & & & \\
5 & -1.16 & $(<0,-)$ & 1.35 \\
10 & -1.17 & $(<0,-)$ & 1.11 \\
15 & -1.26 & $(<0,-)$ & 0.84 \\
\hline
\end{tabular}

*Adjusted for age, birth cohort, race, gender, SES, employment status, in vivo monitoring, and work in plutonium jobs.

Likelihood ratio test, one degree of freedom, comparing full models with models that omit the parameter for cumulative doses at all ages.

Estimates of ERR/Sv for cumulative doses accrued at ages $55+$ were 3.24 (0.80 to 6.17) and 9.05 (2.96 to 17.92) for all cancer and lung cancer, respectively, under a 10 year lag; LRT values were 5.06 and 7.33 , respectively. Coefficients were somewhat larger, and LRT values smaller, under a 15 year lag. A specific association between cancer mortality and radiation doses accrued at older ages has been reported previously in studies of Hanford workers that estimated weighting functions for age specific doses. ${ }^{67}$ Kneale and Stewart estimated a doubling dose of $45 \mathrm{mSv}$ at ages 58+ with a 14 year lag, and $8 \mathrm{mSv}$ at ages $62+$ with a 17 year lag. ${ }^{7}$ Our approach, which considers fixed age windows and lags, is not sensitive to risks that might be specific to smaller age ranges. However, the statistical power to evaluate exposure effects in small time windows diminishes rapidly as distributions of cumulative doses shift to lower values within narrower age bands, reducing the range over which a doseresponse relation can be estimated. We used time window analyses to ensure that dose-response coefficients are estimated over a substantial range of dose. In our study, age specific cumulative dose distributions (table 4), which depend on age specific employment periods (table 3 ), were broad enough to estimate dose-response between zero and approximately $300 \mathrm{mSv}$ (table 7).

Variation in radiation risks by age-at-exposure in Oak Ridge National Laboratory (ORNL) workers was examined using two time windows defined by age at exposure, and the boundary between these windows was modified to search for the age that best discriminated between radiation risks for younger and older ages. The size and dose distribution of the Hanford cohort permitted specification of four age windows to evaluate whether there is a gradual increase in radiation risk with advancing age, an observation that would be consistent with biological mechanisms including age related declines in cellular repair and immune function. In contrast to this expectation, all cancer and lung cancer show an abrupt increased ERR ages of exposure above 55. An abrupt increase was also suggested in analyses of the ORNL cohort using age weighting functions rather than age windows; at ORNL the best fitting age boundary was 45 years. ${ }^{34}$ An additional similarity of age-window analyses of cancer mortality at ORNL and Hanford is that dose coefficients for younger ages, although they are imprecise and contribute little to model fit, tend to be negative. This pattern was also observed in a recent study of multiple myeloma among workers from four US nuclear weapons sites. ${ }^{35}$ Negative or absent radiation risks for doses accrued at younger ages could result from uncontrolled confounding from internal healthy worker selection that is stronger at younger than at older ages, whereas positive risks for doses at older ages could result from uncontrolled confounding by smoking or other exposures if they were positively associated with radiation doses accrued at older but not younger ages.

Table 6 Excess relative risk per Sv at specific ages, 5, 10, and 15 year lag assumptions, follow up of Hanford Site workers through 1994

\begin{tabular}{|c|c|c|c|c|c|}
\hline \multirow{2}{*}{\multicolumn{2}{|c|}{$\begin{array}{l}\text { Cause of death } \\
\text { Lag (years) }\end{array}$}} & \multicolumn{4}{|c|}{ Age range of cumulative dose } \\
\hline & & Ages 16 to 34 & Ages 35 to 44 & Ages 45 to 54 & Ages 55 to 82 \\
\hline \multicolumn{6}{|c|}{ All causes } \\
\hline \multirow[t]{2}{*}{5} & $\operatorname{ERR}(90 \% \mathrm{CI})$ & $0.09(-1.39$ to 1.79$)$ & $-0.82(-1.81$ to 0.24$)$ & $0.22(-0.72$ to 1.22$)$ & $0.27(-0.69$ to 1.30$)$ \\
\hline & LRT† & 0.01 & 1.65 & 0.14 & 0.20 \\
\hline \multirow[t]{2}{*}{10} & ERR $(90 \% \mathrm{CI})$ & $-0.28(-1.81$ to 1.48$)$ & $-0.27(-1.30$ to 0.85$)$ & $-0.26(-1.21$ to 0.75$)$ & $0.38(-0.67$ to 1.51$)$ \\
\hline & LRT† & 0.08 & 0.16 & 0.19 & 0.33 \\
\hline \multirow[t]{2}{*}{15} & $\operatorname{ERR}(90 \% \mathrm{Cl})$ & $-0.20(-1.77$ to 1.64$)$ & $-0.22(-1.29$ to 0.96$)$ & $-0.26(-1.23$ to 0.79$)$ & $0.02(-1.18$ to 1.37$)$ \\
\hline & LRT† & 0.04 & 0.10 & 0.18 & 0.00 \\
\hline \multicolumn{6}{|c|}{ All cancers } \\
\hline \multirow[t]{2}{*}{5} & ERR $(90 \% \mathrm{Cl})$ & $2.08(-1.10$ to 6.08$)$ & $-0.71(-2.53$ to 1.38$)$ & $-0.55(-2.16$ to 1.27$)$ & $2.27(0.22$ to 4.65$)$ \\
\hline & LRT $†$ & 1.05 & 0.34 & 0.27 & 3.35 \\
\hline \multirow[t]{2}{*}{10} & $\operatorname{ERR}(90 \% \mathrm{CI})$ & $1.88(-1.38$ to 6.03$)$ & $0.04(-1.89$ to 2.25$)$ & $-1.45(-3.11$ to 0.43$)$ & $3.24(0.80$ to 6.17$)$ \\
\hline & LRT† & 0.80 & 0.00 & 1.65 & 5.06 \\
\hline \multirow[t]{2}{*}{15} & ERR $(90 \% \mathrm{Cl})$ & $2.21(-1.10$ to 6.46$)$ & $-0.43(-2.29$ to 1.74$)$ & $-1.14(-2.82$ to 0.85$)$ & $3.27(0.13$ to 7.20$)$ \\
\hline & $\mathrm{LRT} \dagger$ & 1.09 & 0.12 & 0.95 & 2.96 \\
\hline \multicolumn{6}{|c|}{ Lung cancers } \\
\hline \multirow[t]{2}{*}{5} & $\operatorname{ERR}(90 \% \mathrm{CI})$ & $-0.67(<0$ to 4.93$)$ & $-0.84(<0$ to 3.20$)$ & $1.06(-1.98$ to 4.98$)$ & 4.59 (0.43 to 10.17$)$ \\
\hline & LRT† & 0.06 & 0.15 & 0.28 & 3.40 \\
\hline \multirow[t]{2}{*}{10} & ERR $(90 \% \mathrm{CI})$ & $-0.84(<0$ to 4.93$)$ & $0.02(<0$ to 4.25$)$ & $-0.54(<0$ to 3.31$)$ & 9.05 (2.96 to 17.92$)$ \\
\hline & LRT† & 0.09 & 0.00 & 0.07 & 7.33 \\
\hline \multirow[t]{2}{*}{15} & ERR $(90 \% \mathrm{Cl})$ & $-0.76(<0$ to 4.98$)$ & $-0.08(<0$ to 4.10$)$ & $0.03(-3.19$ to 4.43$)$ & $10.28(2.42$ to 22.52$)$ \\
\hline & LRT† & 0.08 & 0.00 & 0.00 & 5.50 \\
\hline
\end{tabular}

*Adjusted for age-at-risk, birth cohort, race, gender, SES, employment status, in vivo monitoring, work in plutonium jobs, and radiation doses in other age groups. thikelihood ratio test, one degree of freedom, comparing models with all four age specific dose terms to models that omit the parameter for the age specific cumulative dose in each column. 
Table 7 Observed and expected deaths from all cancer and lung cancer according to cumulative doses at ages 55 and above, 10 year lag, follow up of Hanford Site workers through 1994

\begin{tabular}{|c|c|c|c|c|c|c|c|c|c|}
\hline \multirow[b]{2}{*}{ Cause of death } & \multicolumn{9}{|c|}{ Radiation dose (mSv) (mean dose ${ }^{\star}$ ) } \\
\hline & $0(0.0)$ & $-10(3.2)$ & $-20(14.1)$ & $-50(31.3)$ & -100 (71.3) & $-150(120.2)$ & $-200(172.3)$ & $-300(239.9)$ & $300+(323.7)$ \\
\hline \multicolumn{10}{|l|}{ All cancer } \\
\hline Observed & 1591 & 419 & 97 & 70 & 42 & 23 & 7 & 15 & 1 \\
\hline O/E† & 0.99 & 0.99 & 0.96 & 1.22 & 1.27 & 1.13 & 0.68 & 1.56 & 0.88 \\
\hline \multicolumn{10}{|l|}{ Lung cancer } \\
\hline Observed & 458 & 119 & 27 & 31 & 10 & 11 & 2 & 8 & 0 \\
\hline O/E† & 0.98 & 0.96 & 0.91 & 1.57 & 0.81 & 1.56 & 0.53 & 2.51 & - \\
\hline
\end{tabular}

${ }^{*}$ Average of the cell specific mean doses in the fully stratified table of person-time.

†Ratio of observed to expected deaths adjusted for age, birth cohort, race, gender, SES, employment status, in vivo monitoring, work in plutonium jobs, and cumulative external dose at ages less than $35,35-44$, and $45-54$.

We fit several additional models (10 year lag) to consider possible alternative explanations for the observed age pattern of radiation risk coefficients. First we evaluated associations between radiation and non-cancer mortality, which is dominated by diseases related to smoking and other lifestyle factors. The age specific ERR/Sv was $-0.96(-2.60$ to 0.99$)$, -0.39 ( -1.60 to 0.94$), 0.11$ ( -1.00 to 1.32$)$, and -0.45 $(-1.54$ to 0.77$)$ for ages below $35,35-44,45-54$, and $55+$, respectively, indicating that doses at ages $55+$ are positively associated with cancer, but not non-cancer mortality. Nonlung cancer mortality, has risk coefficients of $3.75(-0.67$ to $9.37),-0.25(-2.54$ to 2.45$),-1.90(<0$ to 0.40$)$, and 1.73 $(-0.77$ to 4.72$)$ for the four age groups, respectively. The lung cancer coefficient for doses at ages 55+ (table 6), is approximately five times larger than the coefficient for other cancers, showing that the relation between older age radiation doses and all cancer mortality is largely due to deaths from lung cancer.

Smoking is an important potential confounder of radiation-lung cancer associations. Observed relations would be spurious if smoking were positively associated with radiation at ages $55+$, but not at younger ages, or if quitting smoking were negatively associated with radiation at ages 55+, but not at younger ages. Smoking status was not routinely noted in medical records during the period 1944-70. A survey of Hanford workers in the 1980s found no clear relation between radiation and smoking, ${ }^{36}$ however, confounding effects of smoking, especially for older ages of exposure, could be due to smoking patterns in the 1940s-1970s.

Birth cohort differences in radiation risk estimates comprise a potential competing explanation of observed age effects. In contrast to intrinsic biological processes that could be involved in age related increases in radiation sensitivity, cohort effects could occur through several extrinsic mechanisms, including systematic dose misclassification specific to older cohorts employed during historical periods of less sensitive monitoring, dose related exposures to other occupational lung carcinogens specific to older cohorts, or radiationsmoking relations specific to older cohorts. Pierce et al suggested that there may be a sub-multiplicative relation between smoking and radiation such that older atomic bomb survivors with lower smoking prevalence show a higher relative risk when analyses use regression models that assume multiplicative relations. ${ }^{15}$

We fit models to explore birth cohort differences in radiation risk estimates for lung cancer among white male Hanford workers $(\mathrm{n}=598$ lung cancer deaths). Analyses were limited to white men, who received $92.8 \%$ of the total radiation dose, because temporal patterns of smoking among white males in the USA during this period differed from other groups. The LRT for addition of four age specific dose terms, as above, was compared with the LRT for inclusion of four interaction terms between cumulative dose (at all ages) and birth cohort, defined as before 1900, 1900-09, 1910-29, and 1930+. The LRT values (4 df) were 14.84 for the four cohort-dose interaction terms compared to 9.28 for the four age specific dose terms. In exponential relative risk models, LRT values were 5.86 for the four cohort-dose interaction terms and 8.00 for the four age specific dose terms. The covariation of exposures by age and cohort, small differences in LRT values between age and cohort models, and model dependence of the direction of the difference, make statistical differentiation of their effects difficult.

Hanford workers with routine potential for plutonium exposure have lower cancer rates than other workers, even after adjusting for SES, employment status, and in vivo monitoring status, ${ }^{25}$ suggesting an internal healthy worker effect possibly related to the Hanford occupational medicine programme, which required additional medical screening for workers entering jobs involving special hazards. ${ }^{37}$ However, lung cancer ERR/Sv values are 24.62 (6.76 to 59.02) for plutonium workers versus 7.02 (1.61 to 15.20) for other Hanford workers. The larger ERR/Sv for plutonium workers could result from internal exposures to alpha emitting radionuclides or other carcinogens used in the chemical separations process or from synergisms between other carcinogens and external radiation.

Although dose-response estimates for radiation and cancer mortality from the Life Span Study of atomic bomb survivors depend on several factors including sex, age at exposure, and attained age, a reasonable "benchmark" estimate of ERR/Sv for all solid cancers, ${ }^{38}$ updated using recent dosimetry, ${ }^{39}$ is 0.42 ( $90 \%$ CI 0.33 to 0.51 ), can be compared to our estimate of $0.28(-0.30$ to 1.00). However, ERRs for all cancer among atomic bomb survivors are lowest for ages-at-exposure above 40, whereas among Hanford workers ERR values for all cancer mortality are highest for ages above 55 , primarily due to their association with lung cancer. Differences between results for worker studies and the Life Span Study, which began follow up five years after the bombings, may be due in part to greater dose related selective mortality of radiosensitive persons among older than younger adult atomic bomb survivors, which would cause more of a downward bias in dose-response at older compared to younger adult ages. ${ }^{40}{ }^{41}$ This effect may be particularly important for lung cancer, which can occur less than five years following exposure to ionising radiation. ${ }^{42}$ Dose-response findings for older ages were neither as strong, nor as specific, as previous reports from Hanford, although they are similar to those for ORNL workers, who had evidence of radiation related cancers for doses above age $45^{43}$ and Santa Susana workers, who showed radiation related cancers for doses above age 50. ${ }^{44}$ These observations contrast with a large international study of nuclear workers, which found no evidence of age increases in radiation risk for all cancer, but an association of doses at all ages with leukaemia except CLL. ${ }^{30}$ 
Table 8 Excess relative risk per Sv at ages below and above 55, all cancer and lung cancer, 10 year lag, for plutonium workers and other workers, Hanford Site workers followed through 1994

\begin{tabular}{|c|c|c|c|c|}
\hline \multirow[b]{2}{*}{ Cause of death } & \multicolumn{2}{|c|}{ Age $<55$} & \multicolumn{2}{|c|}{ Age $\geqslant 55$} \\
\hline & ERR/Sv & $(90 \% \mathrm{Cl})$ & ERR/Sv & $(90 \% \mathrm{Cl})$ \\
\hline \multicolumn{5}{|l|}{ All cancer } \\
\hline Non-Pu workers & 0.03 & $(-0.79$ to 1.07$)$ & 2.03 & $(-1.45$ to 8.96$)$ \\
\hline Pu workers & -0.91 & $(<0$ to 0.37$)$ & 2.68 & $(-0.22$ to 4.83$)$ \\
\hline \multicolumn{5}{|l|}{ Lung cancer } \\
\hline Non-Pu workers & -0.37 & (<0 to 1.64$)$ & 7.02 & $(1.61$ to 15.20$)$ \\
\hline Pu workers & 0.14 & i<0 to 4.82$)$ & 24.62 & (6.76 to 59.02 ) \\
\hline
\end{tabular}

Direct evidence of radiation risk at low doses and low dose rates from cohort studies of badge monitored radiation workers will be of increasing value as workers are followed for longer periods and statistical power increases due to additional deaths. Longer follow up will be particularly informative for investigation of time related factors including age and cohort differences in radiation risk.

\section{ACKNOWLEDGEMENTS}

The authors thank Susanne Wolf, Gary Mihlan, Wendy McKelvey, and Edwin van Wijngaarden for insights and input in data collection and analysis.

\section{Authors' affiliations}

S Wing, D B Richardson, Department of Epidemiology, School of Public Health, University of North Carolina, USA

Funding: National Institute for Occupational Safety and Health Grant No. R01/CCR412931, and The lonizing Radiation \& Human Health Fund of The Oregon Community Foundation; Grant No. 2001-00285.

Competing interests: none declared

\section{APPENDIX}

The relation between death rates and radiation dose was quantified via Poisson regression analyses. The model used to estimate rate ratios was the stratified excess relative rate model which is sometimes termed the stratified linear rateratio model (Greenland, 1998). Assuming the study data are divided into $\mathrm{K}$ strata indexed by $\mathrm{k}=1 \ldots \mathrm{K}$, this model takes the form

$$
\mathrm{I}_{\mathrm{k}}(\mathrm{x})=\exp \left(\alpha_{\mathrm{k}}\right)(1+\mathrm{x} \beta),
$$

where $I_{k}(x)$ is the death rate in stratum $k$ at cumulative radiation dose level $\mathrm{x}$. Within each stratum the death rate varies with radiation dose, $\mathrm{x}$; and, only the model intercept, $\alpha_{k}$, changes across strata of study covariates. $\beta$ describes the linear relation between excess relative rate and radiation dose.

Because of the form of equation (1), the possible values of $\beta$ are limited by the requirement that the corresponding relative rate should not be negative. The minimum value for $\beta$ is given by $-1 / x_{\max }$ where $x_{\max }$ is the maximum dose value assigned to a cell of the person-time table. If the likelihood being sought for a point or bound estimate requires a $\beta$ less than this value, then no convergence will be obtained and the estimate is shown as $<0$. The approach of calculating confidence intervals using the standard error for $\beta$ (that is, the Wald method) is known to perform poorly for the linear rate-ratio model since the log likelihood is asymmetric (Lustbader and Moolgavkar, 1987; Prentice and Mason, 1986). We therefore report likelihood based confidence intervals for parameters when the linear rate-ratio model was used.
Exponential relative rate models (Greenland, 1998) were also fit as part of our analysis of these data. The exponential relative rate model takes the form

$$
\mathrm{I}_{\mathrm{k}}(\mathrm{x})=\exp \left(\alpha_{\mathrm{k}}+\mathrm{x} \beta\right),
$$

where $\exp \left(\alpha_{\mathrm{k}}\right)$ is the stratum specific rate when $\mathrm{x}=0$ and $\beta$ represents the change in the log rate that would result from a one unit change in $\mathrm{x}$.

\section{Citations}

Greenland S. Introduction to regression modeling. In: Rothman K, Greenland S, eds. Modern epidemiology, 2nd edn. Philadelphia: Lippincott, Williams, \& Wilkins, 1998.

Lustbader ED, Moolgavkar SH. Some problems of inference in cohort studies. $J$ Chron Dis 1987;40(suppl 2):133S-7S.

Prentice RL, Mason MW. On the application of linear relative risk regression models. Biometrics 1986;42:109-20.

\section{REFERENCES}

1 National Research Council, Committee on the Biological Effects of lonizing Radiation (BEIR V). Health effects of exposure to low levels of ionizing radiation (BEIR V). Washington, DC: National Academy Press, 1990.

2 United Nations Scientific Committee on the Effects of Atomic Radiation. Sources and effects of ionizing radiation. New York: United Nations, 2000.

3 Mancuso TF, Stewart AM, Kneale GW. Radiation exposures of Hanford workers dying from various causes. Tenth Midyear Symposium of the Health Physics Society. NY: Saratoga Springs, 11-13 October, 1976.

4 Mancuso TF, Stewart A, Kneale G. Radiation exposures of Hanford workers dying from cancer and other causes. Health Phys 1977;33:369-85.

5 Kneale GW, Mancuso TF, Stewart AM. Hanford radiation study III: a cohort study of the cancer risks from radiation to workers at Hanford (1944-77 deaths) by the method of regression models in life-tables. $\mathrm{Br} J$ Ind Med $1981 ; 38: 156-66$

6 Kneale GW, Mancuso TF, Stewart AM. Job related mortality risks of Hanford workers and their relation to cancer effects of measured doses of external radiation. Br J Ind Med 1984;41:9-14.

7 Kneale GW, Stewart AM. Reanalysis of Hanford data: 1944-1986 deaths. Am J Ind Med 1993;23:371-89.

8 Kneale GW, Stewart AM. Factors affecting recognition of cancer risks of nuclear workers. Occup Environ Med 1995:52:515-23.

9 Stewart AM, Kneale GW. Relations between age at occupational exposure to ionising radiation and cancer risk. Occup Environ Med 1996;53:225-30.

10 Gilbert ES, Petersen GR, Buchanan JA. Mortality of workers at the Hanford site: 1945-1981. Health Phys 1989;56:11-25.

11 Gilbert ES, Marks S. An updated analysis of mortality of workers in a nuclear facility. Radiat Res 1980;83:740-1.

12 Gilbert ES, Cragle DL, Wiggs LD. Updated analyses of combined mortality data for workers at the Hanford Site, Oak Ridge National Laboratory, and Rocky Flats Weapons Plant. Radiat Res 1993;136:408-21.

13 Goukassian D, Gad F, Yaar M, et al. Mechanisms and implications of the age-associated decrease in DNA repair capacity. J Faseb 2000;14:1325-34.

14 Moriwaki S, Ray S, Tarone RE, et al. The effect of donor age on the processing of UV-damaged DNA by cultured human cells: reduced DNA repair capacity and increased DNA mutability. Mutat Res 1996;364:117-23.

15 Pierce DA, Sharp GB, Mabuchi K. Joint effects of radiation and smoking on lung cancer risk among atomic bomb survivors. Radiat Res 2003;159:511-20.

16 Checkoway H, Pearce N, Hickey JL, et al. Latency analysis in occupational epidemiology. Arch Environ Health 1990;45:95-100.

17 Boyle CA, Decoufle P. National sources of vital status information: extent of coverage and possible selectivity in reporting. Am J Epidemiol 1990;131:160-8

18 Richardson D, Wing S, Schroeder J, et al. lonizing radiation and chronic lymphocytic leukemia. Environ Health Perspect 2005;113:1-5. 
19 Gilbert ES. A study of detailed dosimetry records for a selected group of workers included in the Hanford Mortality Study. Richland, WA: Pacific Northwest Laboratory, 1990.

20 Richardson D, Wing S, Watson J, et al. Missing annual external radiation dosimetry data among Hanford workers. J Expo Anal Environ Epidemiol 1999;9:575-85

21 Buschbom RL, Gilbert ES. Summary of recorded external radiation doses for Hanford workers, 1944-1989. Richland, WA: Pacific Northwest Laboratory, 1993.

22 Wood JW, Richardson DB, Wing S. A simple program to create exact persontime data in cohort analyses. Int J Epidemiol 1997;26:395-9.

23 Richardson D, Wing S, Steenland K, et al. Time-related aspects of the healthy worker survivor effect. Ann Epidemiol 2004;14:633-9.

24 Stewart AM. Healthy worker and healthy survivor effects in relation to the cancer risks of radiation workers. Am J Ind Med 1990;17:151-4.

25 Wing S, Richardson D, Wolf S, et al. Plutonium-related work and causespecific mortality at the United States Department of Energy Hanford Site. Am J Ind Med 2004;45:153-64.

26 Preston DL, Lubin JH, Pierce DA, et al. Epicure: user's guide. Seattle, WA: Hirosoft International Corporation, 1993.

27 Checkoway H, Pearce N, Crawford-Brown DJ, et al. Radiation doses and cause-specific mortality among workers at a nuclear materials fabrication plant. Am J Epidemiol 1988;127:255-66.

28 Greenland S. Randomization, statistics, and causal inference. Epidemiology 1990;1:421-9.

29 Poole C. Low P-values or narrow confidence intervals: which are more durable? Epidemiology 2001;12:291-4.

30 Cardis E, Gilbert E, Carpenter L, et al. Combined analyses of cancer mortality among nuclear industry workers in Canada, the United Kingdom and the United States of America. Lyon, France: World Health Organisation, International Agency for Research on Cancer, 1995.

31 Ashmore JP, Krewski D, Zielinski JM, et al. First analysis of mortality and occupational radiation exposure based on the National Dose Registry of Canada. Am J Epidemiol 1998;148:564-74.
32 Beral V, Fraser P, Carpenter L, et al. Mortality of employees of the Atomic Weapons Establishment, 1951-82. BMJ 1988;297:757-70.

33 Wing S, Shy CM, Wood JL, et al. Mortality among workers at Oak Ridge National Laboratory. Evidence of radiation effects in follow-up through 1984. JAMA 1991;265:1397-402.

34 Richardson DB, Wing S. Methods for investigating age differences in the effects of prolonged exposures. Am J Ind Med 1998;33:123-30.

35 Wing S, Richardson DB, Wolf $S$, et al. A case control study of multiple myeloma at four nuclear facilities. Ann Epidemiol 2000;10:144-53.

36 Petersen GR, Gilbert ES, Buchanan JA, et al. A case-cohort study of lung cancer, ionizing radiation, and tobacco smoking among males at the Hanford Site. Health Phys 1990;58:3-11.

37 Cantril ST. Industrial Medical Program Hanford Engineer Works. Oak Ridge TN: United States Atomic Energy Commission, Technical Information Division, Oak Ridge Directed Operations, 1946.

38 Preston DL, Shimizu Y, Pierce DA, et al. Studies of mortality of atomic bomb survivors. Report 13: Solid cancer and noncancer disease mortality, 19501997. Radiat Res 2003;160:381-407.

39 Preston DL, Pierce DA, Shimizu Y, et al. Effect of recent changes in atomic bomb survivor dosimetry on cancer mortality risk estimates. Radiat Res 2004; 162:377-89.

40 Stewart AM, Kneale GW. A-bomb survivors: factors that may lead to a re-assessment of the radiation hazard. Int J Epidemio 2000;29:708-14.

41 Stewart AM, Kneale GW. A-bomb survivors: further evidence of late effects of early deaths. Health Phys 1993;64:467-72.

42 Langholz B, Thomas D, Xiang A, et al. Latency analysis in epidemiologic studies of occupational exposures: application to the Colorado Plateau uranium miners cohort. Am J Ind Med 1999;35:246-56.

43 Richardson DB, Wing S. Greater sensitivity to ionizing radiation at older age: follow-up of workers at Oak Ridge National Laboratory through 1990. Int J Epidemiol 1999;28:428-36.

44 Ritz B, Morgenstern H, Moncau J. Age at exposure modifies the effects of lowlevel ionizing radiation on cancer mortality in an occupational cohort. Epidemiology 1999;10:135-40.

Answers to questions on Regression modelling and other methods to control confounding by $\mathrm{R}$ McNamee, on pages 500-506

(1) $\mathrm{T}$; (2) $\mathrm{F}$; (3) $\mathrm{T}$; (4) $\mathrm{T}$; (5) F 